\title{
A RENOVAÇÃO DO POSITIVISMO JURÍDICO SOB A PERSPECTIVA DE SUA VERSÃO INCLUSIVISTA
}

Loiane Prado Verbicaro*

Flávia Góes Costa Ribeiro**

SUMÁRIO: Introdução; 2 As reformulações do positivismo jurídico; 3 Direito e moral: uma relação contingente; 4 A Reformulação - e não a superação definitiva - da perspectiva positivista de se conceber, compreender e aplicar o direito; 5 Conclusão; Referências.

RESUMO: As considerações apresentadas na presente pesquisa giram em torno da desmistificação do senso comum e dos discursos falaciosos sobre a teoria positivista do direito, a qual é alvo de más compreensões e interpretações por parte da academia, de forma que se busca demonstrar que tal doutrina, atualmente, a despeito dos questionamentos, não foi superada. Para isto, por intermédio de pesquisa teórica e a partir do estudo de autores da filosofia analítica, este artigo aborda, nos seus três capítulos, as reformulações do positivismo jurídico, a relação contingente entre direito e moral e a reformulação - e não a superação definitiva - da perspectiva positivista de se conceber, compreender e aplicar o direito. O trabalho apresenta como hipótese que não se está diante de uma transformação inovadora e ruptural na forma de se interpretar e de se conceber o direito, tal como proposta pela doutrina do neoconstitucionalismo, mas sim, está diante de reformulações e adaptações do próprio positivismo jurídico, transmudado no refinado positivismo jurídico inclusivo, sendo este capaz de conciliar direito e moral por meio de uma relação contingencial.

PALAVRAS-CHAVE: Direito; Moral; Positivismo jurídico; Paradigma dominante; Positivismo jurídico inclusivo.

\section{RENEWAL OF JURIDICAL POSITIVISM FROM THE PERSPECTIVE OF ITS INCLUSIVE STANCE}

ABSTRACT: Demystification of common sense and fallacious discourses on the positivist theory of Law is provided. In fact, it is wrongly understood and interpreted

Doutora em Filosofia do Direito pela Universidade de Salamanca; Coordenadora da Graduação e Vice-Coordenadora do Programa de Pós-Graduação em Direito do Centro Universitário do Pará, Brasil.

E-mail: loianeverbicaro@uol.com.br

* Graduada em Direito pelo Centro Universitário do Pará; Assessora Jurídica junto à Procuradoria-Geral do estado do Pará (Cesupa), Brasil. 
by specialists. The paper demonstrates that the doctrine has not been displaced, in spite of several questionings. Through theoretical research and studies on the doctrine of analytic philosophy, current analysis deals with reformulation of juridical positivism, the contingent relationship between law and ethics and the reformulation (not final debunking) of the positivist perspective in conceiving, understanding and applying the law. Current hypothesis states that there is no renewing and splitting transformation in the way one interprets and conceives Law, as suggested by the Neo-Constitutionalist doctrine. There are reformulations and adaptations of Juridical Positivism transformed into a refined Inclusive Juridical Positivism capable of reconciling Law and Morality through a contingent relationship.

KEY WORDS: Law; Morality; Juridical Positivism; Dominant paradigm; Inclusive Juridical Positivism.

\section{LA RENOVACIÓN DEL POSITIVISMO JURÍDICO BAJO LA PERSPECTIVA DE SU VERSIÓN INCLUSIVA}

RESUMEN: Las consideraciones presentadas en la presente investigación giran alrededor de la desmitificación del sentido común y de los discursos engañosos sobre la teoría positivista del Derecho, la cual es blanco de más comprensiones e interpretaciones por parte de la academia, de forma que se busca demonstrar que tal doctrina, actualmente, a pesar de los cuestionamientos, no fue superada. Para esto, por intermedio de investigación teórica y a partir del estudio de autores de la filosofía analítica, este artículo aborda, en sus tres capítulos, las reformulaciones del positivismo jurídico, la relación contingente entre derecho y moral y la reformulación - y no la superación definitiva - de la perspectiva positivista de concebirse, comprender y aplicar el derecho. El estudio presenta como hipótesis que no se está delante de una transformación innovadora y de rotura en la forma de interpretarse y de concebirse el Derecho, tal como propuesta por la doctrina del Neo constitucionalismo, sino que se está delante de reformulaciones y adaptaciones del propio Positivismo Jurídico, transmudado en el refinado Positivismo Jurídico Inclusivo, siendo este capaz de conciliar Derecho y moral por intermedio de una relación circunstancial.

PALABRAS CLAVE: Derecho; Moral; Positivismo Jurídico; Paradigma Dominante; Positivismo Jurídico Inclusivo. 


\section{INTRODUÇÃO}

Com a crise da modernidade, consolidou-se a crença de decadência do positivismo jurídico, associada à derrocada dos regimes totalitários do pós-guerra que, distanciando-se das ideias de fetiche da lei e do formalismo acrítico que serviram de disfarce para autoritarismos de matizes variados, ensejaram a necessidade de repensar o papel do direito e da moralidade no interior dos regimes políticos. Como consequência dessa realidade, consolidou-se um novo constitucionalismo democrático e a ideia de valorização dos direitos humanos.

Com essas mudanças, vivenciou-se a incorporação de valores morais nas constituições das principais democracias, o que permitiu o ingresso de princípios de justiça que formam a raiz dos direitos humanos. E em razão da realidade contraditória, pelo menos a priori, entre o positivismo jurídico e sua perspectiva de neutralidade valorativa versus a fundamentação moral-valorativa dos direitos humanos, o positivismo jurídico, acusado de autodestruir-se, promoveu algumas mudanças em sua teoria, culminando em correntes reformuladas, que tentam (re) afirmar a tese da separabilidade entre direito e mora ${ }^{03}$ sob novos argumentos, seja afirmando a conexão contingente, seja defendendo a impossibilidade conceitual da relação entre direito e moral a partir de argumentos mais sofisticados.

Para certas versões do positivismo jurídico, entretanto, alguns autores partiram de uma falsa percepção de que as críticas das teorias rivais ao positivismo estavam corretas. Para essa versão, o positivismo jurídico continua apresentandose como teoria plausível e viável, capaz de explicar adequadamente o direito, seja com a pressuposição da ideia de que as críticas das teorias rivais partiram de incompreensões da teoria positivista e, nesse sentido, o aparente ataque não realizou nenhuma crítica real e efetiva ao positivismo, seja considerando a recuperação e/ ou atualização do modelo positivista para adequar-se e responder à tentativa de ataque desconstrutivista. Trata-se do modelo hegemônico no mundo anglo-saxão, dominado pela filosofia analítica. Nesse contexto, o Brasil, preponderantemente, cultivou a ideia de que o positivismo fora superado em definitivo.

Uma das versões renovadas refere-se ao positivismo jurídico inclusivo ou

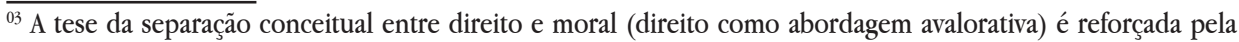
tese positivista das fontes sociais do direito, segundo a qual o direito é um produto humano, convencional, cuja identificação depende exclusivamente de fatos sociais, sem que seja necessário recorrer a valorações ou argumentos morais. Trata-se de uma definição neutral do direito, o que o compatibiliza com a neutralidade dos Estados Liberais de Direito.
} 
positivismo moderado (soft positivism), que defende a tese de que, a despeito de não existir uma conexão conceitual e necessária entre direito e moral, critérios morais podem fazer parte do direito e tal ideia não ameaça a tese positivista da separabilidade, bem como não se coaduna com qualquer versão apresentada pelas teorias jusnaturalistas ou mesmo com a teoria interpretativista de Ronald Dworkin, muito embora se reconheça que há elementos da descrição dworkiniana de sua teoria normativa que são compatíveis com esta versão inclusivista do positivismo jurídico.

De acordo com essa versão renovada do positivismo, a moral política intervém na determinação do sentido dos textos constitucionais que reconhecem direitos e liberdades na determinação do impacto das diversas disposições desses mesmos textos sobre a validade das normas. A moral política se vê, pois, incluída "dentro de los fundamentos posibles para establecer la existencia y el contenido de las leyes positivas válidas, es decir, de las leyes sancionadas o creadas por seres humanos por medio de legislaturas, tribunales o la práctica consuetudinaria". ${ }^{04}$ Referida conexão, no entanto, pode produzir-se ou não e mesmo que não se produza, não deixará de ser um autêntico sistema jurídico, ainda que profundamente injusto.

O positivismo jurídico inclusivo propõe-se, na verdade, a construir uma alternativa intermediária entre a ciência pura do direito e sua descrição moralmente neutral que reflete a isenção a toda influência valorativa da ética, da política, da teoria social, tal como concebida por Hans Kelsen e as concepções dworkinianas que apregoam o valor intrinsecamente moral da prática jurídica. Trata-se de um tema central para as discussões da teoria contemporânea do direito, a fim de que se possa compreender os equívocos em torno do positivismo jurídico e, assim, avaliar a viabilidade de desconstrução e refutação das incompreensões de que foi alvo, para se ter uma análise apurada do debate atual acerca dos modelos teóricos dominantes no âmbito da filosofia analítica.

Para a compreensão adequada desse debate, o trabalho, por intermédio de pesquisa teórica e explicativa, a partir dos autores e discussões da filosofia analítica, que se situa no contexto anglo-saxônico da common law, propõe-se a analisar, no primeiro capítulo, as reformulações do positivismo jurídico; no segundo, a relação contingente entre direito e moral; e, por fim, no terceiro capítulo, a reformulação - e não a superação definitiva - da perspectiva positivista de se conceber, compreender

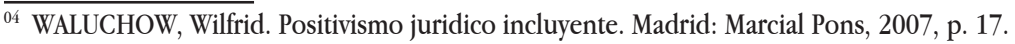


e aplicar o direito, no afã de estabelecer novas luzes ao debate em torno da teoria positivista contemporânea.

\section{AS REFORMULAÇÕES DO POSITIVISMO JURÍDICO}

A doutrina positivista do direito foi - e continua sendo - veementemente alvo de severas críticas por parte de seus opositores. Diante disso, o positivismo, atualmente, tem passado por mudanças - através do positivismo jurídico inclusivo -, no intuito de se adequar ao desenvolvimento do direito e da própria sociedade. Contudo, mais do que isso, tal escola não pretende abrir mão do status que detém: de ser a doutrina hegemônica, a qual se tornou o paradigma dominante.

Neste passo, cabe lembrar que o debate entre Hart e Dworkin enriqueceu os discursos jurídico-filosóficos dentro do direito, ocasionando, por conseguinte, diversas teorias pós- hartianas, a exemplo do positivismo jurídico inclusivo.

Porém, antes de se abordar especificamente as reformulações por quais passara o positivismo, atenta-se à divisão trinária que se encontra hoje na seara da filosofia do direito no que tange aos tipos de positivismo. São eles: positivismo jurídico exclusivo, positivismo jurídico inclusivo e positivismo jurídico normativo. $\mathrm{O}$ ponto em comum entre as três vertentes é o fato de o direito constituir-se em uma criação humana e a não obrigatoriedade de conexão entre direito e moral.

Sendo assim, para o positivismo exclusivo - aquele encontrado nas obras de Raz (The authority of law: essays on law and morality), Marmor (Exclusive legal positivismo) e Shapiro (Legality) -, há uma negação completa da tese da incorporação da moral ao fenômeno jurídico, isto é, a ciência jurídica prescinde de critérios morais, os quais seriam incompatíveis com o próprio conceito de direito. Assim, "direito justo" seria quase um paradoxo, visto que seu traço fundamental não estaria - e nem poderia estar - relacionado a algum elemento axiológico. Segundo Dimoulis, ${ }^{05}$ essa corrente revela que a moral, em nenhuma hipótese, poderia ser utilizada como critério de identificação do direito positivo, seja da constatação de sua validade, seja da realização de sua interpretação.

A este respeito, o próprio $\mathrm{Raz}^{06}$ aduz que, até quando a norma refere-

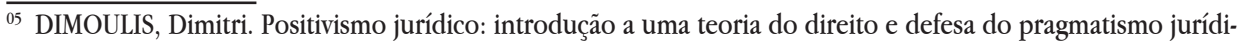
co-político. São Paulo: Método, 2006, p. 135.

${ }^{06}$ RAZ, Joseph. The authority of law: essays on law and morality. Oxford: Oxford University Press, 1979, p. 37-52.
} 
se expressamente a um conteúdo substancial, isso não transforma a natureza da moral, ou seja, a moral nunca poderá ser jurídica, uma vez que o único elemento juridicamente fundamental é a norma criada e posta de forma legítima, independentemente de conteúdos e intenções do legislador. Ora, encontra-se, aqui, como dito, uma versão rigorosa da tese da separação entre direito o moral.

Ademais, Marmor ${ }^{07}$ revela que o tipo de positivismo exclusivo que tem em mente seria aquele que defende, basicamente, que a validade da norma esgota-se nas fontes convencionais da lei, em outras palavras: "[... ] all law is source based, and anything which is not source based is not law.".

Por isso, a crítica deste autor dirigida à versão inclusiva do positivismo reflete-se no fato de que esta variante renovada acredita que há um "intervalo" (gap) entre regras e sua aplicação, sendo que este hiato pode ser conectado (bridged) mediante critérios morais e políticos. Afinal, para o autor, a falha desta vertente está, justamente, no fato de que não há nenhum "buraco" entre as regras e suas respectivas aplicações e, portanto, não haveria necessidade de se recorrer a premissas valorativas. $^{08}$

Entretanto, de fato, afirmar que a moral nunca interfere conceitualmente no sentido do direito é algo juridicamente impossível, senão quando socialmente impossível. Esse sentido do positivismo jurídico torna a conciliação entre a doutrina positivista e o constitucionalismo democrático quase intolerável, visto que os obstáculos postos para tanto são praticamente intransponíveis e impermeáveis. Por isso, o presente trabalho não abraça essa versão da escola positivista.

Por outro lado, o positivismo liclusivo - encabeçado por Coleman (Negative and positive positivism), Waluchow (Positivismo juridico incluyente), Himma (Inclusive legal positivism) e Kramer (In defense of legal positivism: law without trimmings) -, acaba por aceitar e, por conseguinte, não negar a tese da incorporação, de modo que os sistemas jurídicos podem, sim, aderir a orientações morais como critérios de validade jurídica das normas. Neste sentido, Dimoulis ${ }^{09}$ afirma que há possibilidades de determinados sistemas jurídicos considerarem a moral como forma de determinação da validade jurídica das normas, porém, nem sempre, os valores morais são decisivos no momento de definir e aplicar o direito.

\footnotetext{
${ }^{07}$ MARMOR, Andrei. Exclusive legal positivism. In: COLEMAN, Jules; Shapiro, Scott (Org.). The Oxford handbook of jurisprudence \& philosophy of law. Oxford: Oxford University Press, 2002, p. 104.

${ }^{08}$ Ibidem, p. 112.

${ }^{09}$ DIMOULIS, op. cit., p. 137.
} 
Os ensinamentos de Himma ${ }^{10}$ permitem concluir que a tese da incorporação da moral ao direito bifurca-se em dois componentes, os quais ele denomina de the sufficiency component e the necessity component. O primeiro deles revela que os sistemas legais cumprem a condição suficiente quando a norma, para ser legalmente válida, reproduz conteúdos morais - caminho escolhido pelos positivistas inclusivos. Já o segundo componente aduz que, nos sistemas jurídicos, há uma condição necessária para que uma norma seja considerada legalmente válida, e esta condição determina que se leve em consideração conteúdos morais, ou seja, não basta que a validade de uma norma legal esteja em uma relação lógica e apropriada para com as outras normas do sistema - modelo defendido pelos adeptos do neoconstitucionalismo.

No mesmo sentido, Coleman ${ }^{11}$ revela haver "critérios de juridicidade de cunho moral" imbricados nos sistemas jurídicos - moral criteria of legality. Além disso, o mesmo autor ainda assim se pronuncia: "O caráter jurídico de normas pode depender algumas vezes de seus méritos substanciais e não somente de sua origem ou fonte social.". ${ }^{2}$

Cabe ressaltar, nesse ínterim, as lições de Hart ${ }^{13}$ acerca da sua tese das regras secundárias de reconhecimento. Tal tese leva em consideração que essas regras podem incluir critérios substanciais como requisitos de validade das normas, ou seja, a moral pode tornar-se relevante no sistema jurídico e isso se dá quando a regra de reconhecimento inclui valores morais.

Desse modo, a vertente que interessa ao presente trabalho é, justamente, a do positivismo jurídico inclusivo, o qual, diferentemente do positivismo exclusivo, revela que os conceitos do direito normativo podem estar em função de determinações e considerações morais, acabando por trazer a possibilidade das normas jurídicas estarem atreladas a um conteúdo moral mínimo. Assim, poder-se-ia dizer que a legalidade estaria condicionada a uma carga de conteúdo moral, isto é, algumas vezes, a validade das regras estaria em uma relação de dependência para com méritos substantivos, relativizando a teoria do pedigree das leis.

\footnotetext{
${ }^{10}$ HIMMA, Kenneth Einar. Inclusive legal positivism. In: COLEMAN, Jules; Shapiro, Scott (Org.). The Oxford handbook of jurisprudence \& philosophy of law. Oxford: Oxford University Press, 2002, p. 136-137.

${ }^{11}$ COLEMAN, Jules. The practice of principle: in defense of a pragmatist approach to legal theory. Oxford: Oxford University Press, 2003, p. 67.

${ }^{12}$ COLEMAN, Jules. Incorporationism, conventionality and the practical difference thesis. In: COLEMAN, Jules (Org.). Hart's postscript: essays on the postscript to the concept of law. Oxford: Oxford University Press, 2001, p. 100 .

${ }^{13}$ HART, H. L. A. O conceito de direito. São Paulo: Martins Fontes, 2012, p. 250.
} 
Já o positivismo normativo visa estabelecer o direito como ele deve ser e não como ele é - e, neste aspecto, diverge das duas vertentes citadas acima, as quais analisam o fenômeno jurídico de forma inversa. Sendo assim, buscando garantir a liberdade e a democracia, essa versão doutrinária defende normas que sejam objetivamente interpretáveis e aplicáveis, bem como detenham caráter público, direto e claro, tendo como adeptos MacCormick, Campbell, Waldron, Schauer.

Diante do exposto, após algumas criteriosas censuras e acusações serem dirigidas ao positivismo jurídico, chega-se ao momento de o mesmo exercer seu direito ao contraditório. Com efeito, chega-se, portanto, aos pontos nevrálgicos da problemática.

Passando, neste momento, propriamente, às reformulações do positivismo, nota-se que a versão moderada (inclusiva) consegue responder às críticas dos seus opositores, ainda que tais críticas sejam baseadas na "falácia do espantalho", visto dirigirem-se suas críticas à caricatura das ideias do adversário, ao invés do verdadeiro conteúdo de seus posicionamentos.

A primeira crítica à escola positivista refere-se acerca da relação entre direito e moral. Como dito alhures, há uma acusação cabal de que tal doutrina prima pela neutralidade axiológica e meramente descritiva do direito. Logo, Finnis ${ }^{14}$ assim pronuncia-se: "If you want to be 'positivist', 'rigorously descriptive' about law as a kind of social fact, you had better be positivist, rigorously descriptive, about morality, too."

Ora, tal argumento não é válido, pois esse não é o sentido do positivismo inclusivo. Muito pelo contrário. Esta vertente acaba por aceitar a incorporação de preceitos morais validamente reconhecidos pelo direito. Nas lições de Bermejo, ${ }^{15} \mathrm{O}$ positivismo inclusivo tem como objeto de referência uma "estrategia de conciliación entre la regla de reconocimiento y moralidad, entre positivismo y moralidad.".

Quando os juízes resolvem determinados casos que lhes são postos à pacificação social, consoante alguns padrões morais, acabam por incorporar ditos conceitos de moralidade na composição do próprio direito juridicamente válido. Nesta senda, Dimoulis e Lunardi ${ }^{16}$ ensinam que o positivismo jurídico não nega a

\footnotetext{
${ }^{14}$ FINNIS, John. Natural law: the classical tradition. In: COLEMAN, Jules; Shapiro, Scott (Org.). The Oxford handbook of jurisprudence \& philosophy of law. Oxford: Oxford University Press, 2002, p. 15.

${ }^{15}$ BERMEJO, Juan Manuel Pérez. Coherencia y sistema jurídico. Madrid: Marcial Pons, 2006, p. 105.

${ }^{16}$ DIMOULIS, Dimitri; LUNARDI, Soraya. O positivismo jurídico diante da principiologia. In: DIMOULIS, Dimitri; DUARTE, Écio Oto (Coord.). Teoria do direito constitucional: superação ou reconstrução do positivismo jurídico?. São Paulo: Método, 2008, p. 190.
} 
conexão do binômio criação-aplicação entre direito e a influência dos valores, já que somente pergunta qual a autoridade competente a decidir em cada caso concreto e quais seriam os limites de seu poder.

Nota-se, com isso, que a aplicação do silogismo lógico formal só pode ser entendida caso houvesse nítida fundamentação de uma moral mínima aplicada pelo magistrado segundo uma norma legal. A moral, portanto, passa a ser um critério que identifica o direito, surpreendentemente, o direito positivo, ainda que inclusivo.

Assim, Dimoulis ${ }^{17}$ salienta que o positivismo jurídico inclusivo não se limita a elaborar uma teoria que apenas descreva de que modo a moral pode influenciar no direito, pois, mais do que isso, acaba-se tentando "salvar" a abordagem positivista do atual descrédito que lhe fora conferido, uma vez que há uma estratégia de concessões ao discurso jusmoralista.

No mesmo sentido, Waluchow, ${ }^{18}$ um dos representantes mais notórios dessa versão renovada do positivismo, aduz que a moral política vê-se, pois, incluída "dentro de los fundamentos posibles para estabelecer la existencia y el contenido de las leyes positivas válidas, es decir, de las leyes sancionadas o creadas por seres humanos por medio de legislaturas, tribunales o la práctica consuetudinaria.".

Ainda assim, há quem defenda que essas "concessões ao discurso jusmoralista" acabam fazendo com que o positivismo adentre em uma contradição com sua própria doutrina. Dworkin ${ }^{19}$ critica esse tipo de positivismo - soft convencionalism, como o denomina -, revelando que ele estaria mascarado, pois, na verdade, é uma atenuação da sua doutrina da integridade, considerando-o como uma "versão subdesenvolvida" de tal teoria, pois, o "verdadeiro Positivismo Jurídico" seria tão somente o exclusivo. Logo, aduz que o positivismo inclusivo torna-se uma doutrina, na verdade, antipositivista, uma vez que derruba as teses centrais do direito positivo. Por isso, Dworkin denominou tal argumento de "argumento do colapso".

As críticas do teórico pós-positivista, segundo Macedo Júnior, ${ }^{20}$ atacavam justamente os alicerces da doutrina positivista de tal forma que a tarefa de se autodefinir "positivista" tornava-se difícil ou, até mesmo, quase impossível.

Porém, o estudioso americano é rebatido por outros que defendem o positivismo jurídico inclusivo como a noção mais adequada de uma doutrina

\footnotetext{
${ }^{17}$ DIMOULIS, Dimitri; LUNARDI, Soraya, 2008, p. 140-141.

${ }^{18}$ WALUCHOW, op. cit., p. 17.

${ }^{19}$ DWORKIN, Ronald. O império do direito. São Paulo: Martins Fontes, 2014, p. 157.

${ }^{20}$ MACEDO JÚNIOR, Ronaldo Porto. Do xadrez à cortesia: Dworkin e a teoria do direito contemporânea. São Paulo: Saraiva, 2014, p. 166.
} 
positivista, pois é a corrente que abarca as características essenciais dos ordenamentos jurídicos das democracias constitucionais contemporâneas. Ora, não seria o positivismo jurídico que colapsa em um antipositivismo, mas sim, a versão do "direito como integridade" de Dworkin que acaba por tornar-se, ela mesma, um tipo de positivismo jurídico. ${ }^{21}$

Cabe frisar, aqui, que Waluchow rebate quatro argumentos de Dworkin contra a tese inclusiva do direito positivo, quais sejam, argumento da validade, do pedigree, da função e da discricionariedade.

Quanto ao primeiro argumento - validade - Waluchow ${ }^{22}$ afirma que não há razões para que se possa supor que determinada lei válida não possa conter uma dimensão de peso, ou seja, não há motivos para se pensar que princípios que contenham peso não possam também satisfazer aos testes de validade encontrados nas regras de reconhecimento.

$\mathrm{O}$ segundo argumento diz respeito ao pedigree normativo. Waluchow ${ }^{23}$ revela que os ataques do doutrinador pós-positivista somente podem ser dirigidos ao positivismo jurídico exclusivo, visto que o inclusivo está comprometido com testes de conteúdo e não somente com testes de fontes validadas juridicamente, caindo por terra, portanto, a afirmação de que o positivismo somente preocupa-se com os testes de pedigree.

Não obstante, cabe ressaltar que Shapiro ${ }^{24}$ - adepto do positivismo exclusivo - considera que os juízes, em certas ocasiões, estão obrigados legalmente em aplicar princípios que carecem de qualquer pedigree institucional, sem que isso impugne a própria tese de Pedigree. Logo, diante de certas situações, quando as regras de pedigree esgotam-se, os juízes ficam submetidos a uma obrigação legal que importa em analisar princípios morais, a fim de resolverem determinado caso que têm em mãos.

Já o argumento da função diz respeito à excessiva crítica que Dworkin faz ao clamor, pelos positivistas, da necessidade por certeza e segurança dentro de um sistema jurídico-normativo. Contudo, novamente, o autor deixa claro que a afirmação não merece prosperar, devido ao fato de muitos positivistas - como Hart

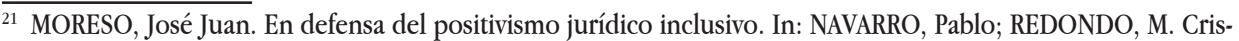
tina (Org.). La relevancia del derecho: ensayos de filosofia moral, jurídica y política. Barcelona: Gedisa, 2002, p. 93.

22 WALUCHOW, op. cit., p. 185.

${ }^{23}$ Idem, 2007, p. 190-192.

${ }^{24}$ SHAPIRO, Scott J. The "Hart-Dworkin" debate: a short guide for the perplexed. Public law and legal theory working paper series, Michigan, n. 47, Mar. 2007. Disponível em: <http://ssrn.com/abstract=968657>. Acesso em: 20 abr. 2015, p. 20-22.
} 
- reconhecerem termos passíveis de flexão e, consequentemente, dotados de uma textura aberta.

Ora, a noção de que uma norma advinda de um teste de pedigree apresenta grau de certeza maior do que as decorrentes de testes de conteúdo não se faz presente na doutrina do positivismo inclusivo, pois, a mesma reconhece que as normas obtidas por meio do critério das fontes podem trazer antinomias a um sistema jurídico e, por outro lado, é capaz de reconhecer que as normas identificadas por critérios de conteúdo podem acabar apresentando alto grau de concordância em determinada sociedade. ${ }^{25}$

Deste modo, deve-se ter em mente que nem sempre a validade da norma dependerá, necessariamente, de critérios morais. Diante disso, o positivismo inclusivo, com cautela e razão, não admite graus morais indeterminados e instáveis que possam advir de uma regra de reconhecimento.

O último argumento é o da discricionariedade. Waluchow ${ }^{26}$ afirma que o fato de se recorrer a argumentos morais mediante a discricionariedade judicial não invalida o positivismo jurídico, justamente pelo fato de ser aceita em várias correntes da mesma doutrina. Ademais, nem todo problema moral pede a resolução por meio da discricionariedade e, assim, não teria cabimento a afirmação dos adversários do positivismo jurídico inclusivo que, segundo a qual, esta versão renovada do direito positivo seria incompatível com a discricionariedade.

$\mathrm{O}$ fato de as propostas de um positivismo renovado englobar um engajamento moral, valorativo e crítico, não significa a destruição da cognição segura e certa da descrição do fenômeno jurídico. Isto impele dizer que a previsibilidade do direito, ainda que relativa devido à inserção de critérios morais, ainda pode ser obtida mediante referência aos fatos sociais concretos, validamente reconhecidos pelo legislador.

Logo, os ordenamentos jurídicos que convencionam que o direito não está imbricadamente ligado à moral não podem ser tidos como injustos ou não válidos, pois apenas não há uma relação necessária entre tais institutos, mas há tão somente uma relação contingente, a qual esta última é defendida pelos adeptos do positivismo inclusivo.

É importante atentar para o fato de que a tese positivista renovada não impõe neutralidade axiológica e descritiva às normas jurídicas e, consequentemente, esta crítica não tem fundamento quando associada ao positivismo inclusivo.

\footnotetext{
${ }^{25}$ WALUCHOW, op. cit., p. 198-205.

${ }^{26}$ Idem, 2007, p. 207-208.
} 
Importa trazer a presente abordagem, a afirmação cabal de Gardner ${ }^{27}$ na qual, para ele, a "tese da conexão não necessária" entre direito e moral é o principal - e o favorito - mito sobre o positivismo jurídico. Aparentemente, tal tese aduz que os positivistas acreditam que não há uma conexão necessária entre tais institutos. Contudo, o autor salienta que tal tese é absurda e nenhum jusfilósofo digno de nota jamais a endossou da forma como referida.

A segunda crítica está relacionada a primeira e tange à inserção dos princípios como normativos. Mais uma vez, a crítica não merece prosperar, pois a versão positivista moderada não nega a existência de princípios morais adequados e vinculantes, quando assim convenciona determinado ordenamento jurídico. Neste interregno, importa trazer à baila o entendimento de Etcheverry, ${ }^{28}$ que, segundo o qual, a virtude do positivismo inclusivo reside na permissão de reconhecer o papel que considerações morais exercem na determinação do direito e, ao admiti-las, não rechaça que o fenômeno jurídico e os critérios que o definem ainda devam possuir uma conexão institucional apropriada.

Os teóricos inclusivistas, como Waluchow, ${ }^{29}$ sustentam que uma teoria jurídica não pode ser um ensaio moralmente neutro da descrição do fato jurídico, isto é, a moral também pode ser útil para justificar proposições descritivoexplicativas. Essa moral, baseada em princípios, acaba por formar juízos jurídicos importantes que influenciam na aplicação do direito e, com efeito, acabam por ter uma conotação normativa.

A este respeito, Lyons ${ }^{30}$ sustenta que o positivismo não exclui os princípios morais como padrões jurídicos, devido ao fato desta escola não negar ou rechaçar os testes de conteúdo. Diante disso, conclui que os positivistas somente afirmam que não é necessário que as regras satisfaçam modelos morais particulares e, com isso, o fato de que essa relação não ocorra necessariamente em virtude de um conteúdo moral, não significa que não possa ocorrer.

No mesmo sentido, Dimoulis e Lunardi ${ }^{31}$ afirmam que: "[...] podemos

\footnotetext{
${ }^{27}$ GARDNER, John. Legal positivism: 5 1/2 myths. American journal of jurisprudence, Notre Dame, v. 46, n. 12, Jan. 2001, p. 222-223. Disponível em: < http://scholarship.law.nd.edu/ajj/vol46/iss1/12/> Acesso em: 21 abr. 2015.

${ }^{28}$ ETCHEVERRY, Juan Bautista. El debate sobre el positivismo jurídico incluyente: un estado de la cuestión. Ciudad de México: Universidad Nacional Autónoma de México, 2006, p. 140.

${ }^{29}$ WALUCHOW, op. cit., p. 31-35.

${ }^{30}$ LYONS, D. Principles, positivism and legal theory. Yale law journal, Connecticut, v. 87, n. 2, Dez. 1977, p. 426. Disponível em: < http://www.jstor.org/stable/795657>. Acesso em: 21 abr. 2015.

${ }^{31}$ DIMOULIS; LUNARDI, op. cit., p. 186.
} 
afirmar que, até prova em contrário, não há juspositivistas assumindo uma postura que ignore ou menospreze os princípios jurídicos positivados.". Até mesmo Raz, ${ }^{32}$ adepto do positivismo jurídico exclusivo, assim se pronuncia por meio de uma crítica endereçada a Dworkin: "A maior preocupação do Professor Dworkin consiste em afirmar que há princípios legalmente vinculantes. Mas nunca ninguém negou isso, e seguramente não o fizeram os positivistas.".

Ainda assim, nesta senda, Macedo Júnior ${ }^{33}$ ensina que os positivistas inclusivos acabaram por aceitar os princípios morais como determinantes para o desempenho de um papel relevante na teoria jurídica, bem como acabaram por reconhecer que tais princípios são jurídicos.

Relevantes são as lições de Himma, ${ }^{34}$ o qual esposa que negar a tese da incorporação da moral ao direito não faz com que os positivistas exclusivistas neguem o óbvio: os sistemas legais, geralmente, incluem, como critério de validade, considerações morais.

A terceira censura às bases do paradigma dominante diz respeito ao fato de este negar a aplicabilidade imediata e direta dos direitos e garantias fundamentais. De fato, essa dimensão irradiante das normas constitucionais contribui para a aproximação de valores emancipatórios contidos nas Constituições contemporâneas.

Todavia, a constitucionalização do direito, louvada pelos neoconstitucionalistas, pode não se tornar legítima sob teses extremadas que acabam por macular a liberdade do legislador em detrimento da democracia.

Defender um Constitucionalismo sem precedentes é incorrer em um curtocircuito jurídico, o qual transforma o legislador em mero executor dos preceitos impostos pelo constituinte, negando, consequentemente, a autonomia política do povo em fazer suas próprias escolhas. ${ }^{35}$

Além disso, os neoconstitucionalistas afirmam que os direitos e garantias fundamentais podem - e em algumas situações devem - limitar interesses majoritários, principalmente quando analisados sob um enfoque cultural. Porém, diferentemente do direito natural, o positivo não se baseia em fatores e valores universalmente válidos, pelo contrário, sua essência é justamente ser mutável e contingente, de

\footnotetext{
${ }_{32}$ RAZ, Joseph. principles and the limits of law. In: COHEN, Marshall (Org.). Ronald Dworkin and contemporary jurisprudence. Totowa: Rowman \& Allanheld, 1984, p. 75.

33 MACEDO JÚNIOR, op. cit., p. 169.

${ }^{34}$ HIMMA, op. cit., p. 140.

35 SARMENTO, Daniel. O neoconstitucionalismo no Brasil: riscos e possibilidades. In: FELLET, André; PAULA, Daniel de; NOVELINO, Marcelo (Org.). As novas faces do ativismo judicial. Salvador: Juspodivm, 2011, p. 109.
} 
modo que acaba por positivar valores e instituições sociais de cada realidade concreta.

Logo, torna-se insubsistente a afirmação de que o direito positivo não protegeria de forma plena e eficaz o princípio da dignidade da pessoa humana, pois, sob a ótica inclusiva, não há negação das dimensões justas, equânimes e morais que circundam tal diretriz normativa, bem como não se faz adequada uma relativização desarrazoada da soberania.

Ora, os sistemas jurídicos que protegem a dignidade da pessoa humana a reconhecem como princípio moralmente adequado e vinculante, basilar de toda a estrutura jurídico-normativa, sem que isso os torne sistemas antipositivistas.

Desta maneira, a crítica de que o positivismo jurídico é uma doutrina construída somente sob o "império da lei", novamente, não ganha fundamento, visto que, como explicado acima, a variante inclusiva acaba por reconhecer que critérios morais que podem validar o direito, principalmente quando reconhecidas pelas próprias normas do sistema.

Desta monta, o "Fetichismo Legal" acaba por ser relativizado. Ensina Alday ${ }^{36}$ que a incorporação da moral ao direito pelos adeptos do positivismo inclusivo é uma realidade evidente, atualmente, em muitos ordenamentos jurídicos, nos quais são abundantes as referências a valores e princípios morais. $\mathrm{O}$ autor continua $\mathrm{O}$ pensamento, revelando que, caso assim não fosse, negar que a moral possa ser uma fonte do direito seria negar a realidade, tendo como consequência uma teoria falsa do direito, visto que careceria de uma descrição adequada dos fatos sociais.

Na mesma linha de raciocínio, são as doutrinas de Dimoulis e Lunardi, ${ }^{37}$ para os quais, não há como se explicar a difusa impressão de hostilidade do positivismo jurídico perante os princípios, senão que essa impressão decorre de outro igualmente difundido - equívoco. Este raciocínio precipitado deve-se ao fato de que muitos críticos acreditam que o positivismo entende a aplicação do direito como procedimento mecânico ou automático, de modo que caberia ao julgador aplicar de maneira "exata" as previsões legislativas. Logo, para estes autores, não há como considerar que os adeptos positivistas sejam "adversários dos princípios".

Ademais, há a crítica ao método hermético e fechado adotado pelo positivismo, acusado de se impor como modelo preciso e completo. Ora, muitos

\footnotetext{
${ }^{36}$ ALDAY, Rafael Escudero. Algunos argumentos frente al positivismo jurídico incluyente. In: DIMOULIS, Dimitri; DUARTE, Écio Oto (Coord.). Teoria do direito constitucional: superação ou reconstrução do positivismo jurídico?. São Paulo: Método, 2008, p. 375.

${ }^{37}$ DIMOULIS; LUNARDI, op. cit., p. 195.
} 
positivistas inclusivos - como Hart - acreditam que o direito positivo não é completo, precisando de técnicas jurídicas para preencher esses espaços. Sendo assim, nota-se que os principais expoentes do positivismo jurídico não estão no modelo dedutivo de interpretação normativa, mas no modelo discricionário, ou seja, reconhecem em maior ou menor medida, o poder discricionário dos juízes.

Neste diapasão, preleciona Gardner ${ }^{38}$ que o positivismo jurídico não é uma teoria completa da natureza do direito, mas se revela em uma doutrina sobre a validade do fenômeno jurídico, a qual é compatível com um extenso número de outras teses sobre a natureza do dDireito, incluindo-se a tese de que todo o direito válido está, por natureza, sujeito a objetivos morais especiais e imperativos próprios.

Diante disso, sejam situações de lacunas, de discricionariedade ou de textura aberta das normas, o direito positivo inclusivo as reconhece, de modo que se acaba deixando de lado o narcisismo calcado na tautologia e solipsismo próprios do positivismo jurídico exclusivo. Logo, tal crítica não ganha força quando imputa à escola positivista moderada.

Por fim, a última censura às concepções positivistas está ligada à crítica supracitada, referente ao problema da discricionariedade judicial. Os defensores neoconstitucionais, baseados na teoria dos princípios, acreditam que não se poderiam compreender os pressupostos positivistas de aplicação subsuntiva da norma aos easy cases e a discricionariedade aos hard cases, sob pena de afronta à democracia.

Contudo, essa "outorga" de um poder criativo do direito a juízes, sem um parâmetro mínimo, a qual poderia ocasionar um reflexo distorcido do conceito aberto de justiça, não é abraçada por doutrinadores positivistas, como Kelsen e Hart.

A este respeito, Kelsen ${ }^{39}$ enxerga que em todas as situações o juiz valese de sua discricionariedade, sendo que essa atividade judicial acaba por ser uma continuação do processo de criação jurídica. Porém, a mesma sempre é limitada pela "moldura legal" imposta pelo próprio ordenamento e, por isso, o jurista não precisaria ater-se a fatores estranhos e externos ao direito, o que acaba por conferir à ciência jurídica um status normativo.

Portanto, pode-se afirmar que a validade de uma decisão judicial assenta-se no fato de ter sido proferida por quem detinha competência segundo uma norma posta e inserida no ordenamento jurídico, resguardando a certeza e segurança do direito - aspectos extremamente caros ao positivismo jurídico.

\footnotetext{
${ }_{38}$ GARDNER, op. cit., p. 210.

${ }^{39}$ KELSEN, Hans. Teoria pura do direito. São Paulo: Martins Fontes, 2000, p. 394.
} 
De outro lado, Hart ${ }^{40}$ considera que o direito é lacunoso e apresenta hard cases e, por conseguinte, para o autor, há discricionariedade quando o juiz deparase diante de lacunas ou casos difíceis, situações que as normas postas não apontam nenhuma solução ao caso concreto. Sendo assim, o juiz criaria o direito, porém restrito a determinado caso concreto - é o que Hart denomina de "poder intersticial".

Além disso, Hart ${ }^{41}$ aduz à denominada "zona de penumbra", a qual também é alcançada pela inevitável existência de um poder discricionário por parte do julgador, tendo em vista a existência do que ele denomina de "textura aberta do direito".

Sendo assim, a confusão entre interpretação e inovação, entre aplicação e produção, entre legislação e jurisdição, entre significado da lei e vontade judicial e entre normas e princípios não pode ser imputada a positivistas como Kelsen e Hart, visto que os mesmos rechaçam severamente a arriscada sucumbência do juiz a decisionismos sem parâmetros legais.

Neste sentido, salientam Duarte e Pozzolo ${ }^{42}$ que a tese central do positivismo inclusivo revela que, no momento de aplicação da norma, os juízes acabam por buscar determinados padrões morais na resolução dos casos jurisdicionais suscitados, de modo que terminam por incorporar ditos conteúdos de moralidade na composição do direito juridicamente válido, sem que com isso sejam utilizados necessariamente critérios extrajurídicos. Com efeito, as normas aplicadas, geralmente, acabam sendo convertidas pela regra de reconhecimento, levando-se em consideração a sua fonte, bem como seu conteúdo, seu valor moral.

No intuito de não deixar dúvidas, são as lições de Dimoulis e Lunardi: ${ }^{43}$ "Assim sendo, o positivismo jurídico relaciona a aplicação dos princípios a uma reflexão sobre o (limite do) poder discricionário de quem os concretiza, podendo escolher entre as possíveis alternativas de interpretação aquela que considerar melhor.".

Ora, nota-se que muitas das críticas imputadas ao paradigma positivista dominante sujeitam-se ao modelo de direito positivo exclusivo e não à reformulada doutrina inclusiva do positivismo jurídico. Por esse fator, afirmou-se que muitos adversários dessa escola acabam por incorrer na straw man fallacy, visto dirigirem

$\overline{40}$ HART, op. cit., 166 .

${ }^{41}$ Ibidem, p. 176.

${ }^{42}$ DUARTE, Écio Oto; POZZOLO, Susanna. Neoconstitucionalismo e positivismo jurídico: as faces da teoria do direito em tempos de interpretação moral da constituição. São Paulo: Landy, 2006, p. 47.

43 DIMOULIS; LUNARDI, op. cit., p. 190. 
suas críticas à caricatura das ideias do adversário, ao invés do verdadeiro conteúdo de seus posicionamentos.

Pode-se dizer que essa doutrina inclusiva funciona como um ponto de equilíbrio e, até mesmo, um contato entre as doutrinas puras do direito positivo e as teorias principiológicas pós-positivistas. Moreso $^{44}$ considera que a noção de positivismo jurídico mais adequada aos ordenamentos jurídicos das democracias constitucionais contemporâneas é a inclusiva, pois consegue conviver com as características do neoconstitucionalismo.

Esse tipo de direito positivo, funcionando como uma intermediação, possibilita a conciliação entre direito e moral e, por conseguinte, a convergência entre o paradigma positivista dominante e o constitucionalismo democrático, pois os princípios morais são validados pelas regras de reconhecimento do sistema jurídico, as quais elevam tais princípios a um status jurídico. Diante disso, a própria ideia da tese da separação entre direito e moral não é abalada, visto que essa relação não é necessária, podendo ocorrer, de fato, uma eventual conexão entre esses dois conceitos, pois a aplicação do direito pelo magistrado é contingente e não necessária.

A este respeito, em que pese ser filiado à versão exclusiva, Shapiro ${ }^{45}$ afirma que, segundo o positivismo inclusivo, a tese da separação não exclui testes que incorporam a moral como critério de validade, concluindo que: "It states simply that tests of legality need not be moralized, not that they could not.".

Ora, no momento em que se afirma que uma regra de reconhecimento socialmente aceita e praticada - portanto, conforme a tese positivista das fontes sociais do direito - pode incorporar padróes morais como critérios de validade jurídica, sem que isso seja um fato necessário, mas mera circunstância - de acordo com a tese da relação contingente entre direito e moral -, abre-se caminho para a defesa de um positivismo consentâneo e contemporâneo com o neoconstitucionalismo.

\section{DIREITO E MORAL: UMA RELAÇÃO CONTINGENTE}

Como se aferiu no tópico anterior, a principal distinção entre neoconstitucionalistas e positivistas inclusivos está no fato do tipo de relação entre direito e moral adotada. Para aqueles há uma relação necessária, enquanto para estes há uma relação contingente.

${ }^{45}$ SHAPIRO, op. cit., p. 23. 
Parece que o grande impasse está na questão se a moral determina o direito como critério de identificação ou justificação. Os neoconstitucionalistas acreditam que a moralidade é um fator crucial para a identificação do fenômeno jurídico, se não menos quando da sua justificação, ou seja, defendem que a moral tanto identifica quanto qualifica (justifica) o direito. Por outro viés, os defensores do positivismo moderado, a exemplo de Hart, salientam que os argumentos jurídicos não são justificados pela moral, porém, aceitam-na como vetor de identificação do direito e, mesmo neste último sentido, a identificação não é necessária, senão contingente.

Ressalta-se, todavia, como exposto alhures, que o positivismo jurídico não se presume completamente alheio aos critérios morais. Ora, até mesmo a doutrina de Rossi ${ }^{46}$ a qual acredita na superação do positivismo pelo neoconstitucionalismo, revela que: "Todos os grandes expoentes do positivismo jurídico jamais negaram a existência de relações, e, muitas vezes, até mesmo a coincidência entre normas morais e normas jurídicas.".

Neste momento, é lícito passar às implicações da relação contingente entre direito e moral. Como já explanado, essa postura é adotada pelos estudiosos inclusivistas, de tal forma que se pode considerar que essa doutrina analisa o direito de um ponto de vista interno e compreensivo, assumindo a possibilidade - não a necessidade - de se relacionar com a moral.

Nas palavras de Pozzolo, ${ }^{47}$ a moral contingente encontra lugar entre as fontes do direito nas teses sustentadas pelo positivismo inclusivo, principalmente aquele de Waluchow, visto que este defende - diferenciando-se de Raz - que a moral é capaz de determinar a existência, o conteúdo e o sentido das normas jurídicas válidas.

Neste diapasão, o próprio Waluchow ${ }^{48}$ assim revela: "Una consecuencia del positivismo incluyente es que las consideraciones morales pueden ser relevantes para la identificación de la existencia y contenido del derecho sólo si el sistema jurídico mismo ha reconocido de algún modo que cumplen ese rol.”.

O autor ainda salienta que o positivismo jurídico inclusivo é uma versão conceitualmente possível do positivismo lato sensu, visto que o fato de incorporar mandamentos morais em nada desprestigia, desqualifica ou destrói teses positivistas. ${ }^{49}$

\footnotetext{
${ }^{46}$ ROSSI, A. Neoconstitucionalismo e a superação da perspectiva positivista do direito. 2011. 210 f. Tese (Doutorado em Direito) - Universidade Federal do Paraná, Curitiba. 2011, p. 85.

${ }^{47}$ POZZOLO, Susanna. Neocostituzionalismo e positivismo giurídico. Torino: Giappichelli, 2001, p. 141.

${ }^{48}$ WALUCHOW, op. cit., p. 127.

${ }^{49}$ Ibidem, p. 182.
} 
Nota-se, então, que os neoconstitucionalistas buscam uma vinculação necessária entre o fenômeno jurídico e a moral, na medida em que é inviável qualquer mandamento jurídico carente de um grau mínimo de moralidade. Os princípios fortaleceriam esse elo - bond -, uma vez que são tidos como integradores e não subsidiários dentro de um sistema jurídico.

O juiz, então, ao decidir, não deve fundamentar-se, pura e simplesmente, no direito posto pelo Estado, mas, acima de tudo, deve buscar referências morais, sob um ponto de vista justificável, no afã de se alcançar uma "pretensão de correção moral", necessariamente vinculada à decisão judicial.

Logo, para Alexy,,$^{50}$ o conceito de direito vai - e deve ir - muito além da mera estrutura jurídico-normativa, de forma que englobe o próprio sistema social, baseado no que ele denomina de "expectativas normativas de comportamento". Assim, as normas jurídicas ou os sistemas jurídicos que não levem em consideração premissas morais mínimas, acabam por perder seu caráter jurídico.

No entanto, os defensores da teoria inclusiva consideram que um ponto de intersecção entre direito e moral é suficiente para que se configure essa conexão e, por isso, é contingencial. Não se nega, repisa-se, a natureza e o caráter determinante dos princípios para a construção de uma moralidade social ou política, pelo fato dessa moralidade ser a existência e o conteúdo das leis. Consoante Alday: ${ }^{51}$ "Adotase, assim, uma teoria da validade do direito que incorpora elementos materiais.".

Vislumbra-se, nesta toada, que a tese inclusivista apregoa que os imperativos morais são cruciais na identificação da validade das normas que compõem determinado ordenamento jurídico, mister quando se trata de sua interpretação. ${ }^{52}$

Neste sentido, citam-se: Waluchow, ${ }^{53}$ o qual revela que a semelhança entre direito e moral deve ser acolhida "com prazer" e bem vista pelos teóricos positivistas; Kramer, ${ }^{54}$ para o qual a não adoção dessa semelhança seria incorrer em uma "tolice" jurídica; Hart, ${ }^{55}$ segundo o qual o direito "acompanha as crenças sociais" e; Coleman, ${ }^{56}$ o qual afirma que, diante de uma constatação empírica, não se pode conceber que direito é determinada coisa enquanto a moral revela-se outra.

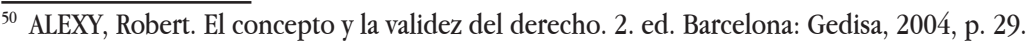

${ }^{51}$ ALDAY, Rafael Escudero. Los calificativos del positivismo jurídico: el dabate sobre la incorporación de la moral. Madrid: Civitas, 2004, p. 76.

${ }^{52}$ DIMOULIS, op. cit., p. 139.

${ }^{53}$ WALUCHOW, op. cit., p. 81.

${ }^{54}$ KRAMER, Matthew. In defense of legal positivism: law without trimmings. Oxford: Oxford University Press, 2003, p. 196.

${ }^{55}$ HART, op. cit., p. 200.

${ }^{56}$ COLEMAN, Jules. Negative and positive positivism. In: COHEN, Marshall (Org.). Ronald Dworkin and the contemporary jurisprudence. Totowa: Rowman \& Allanheld, 1984, p. 31.
} 
Pelo exposto, depreende-se que o positivismo inclusivo renova os postulados do positivismo lato sensu, aceitando a inconteste normatividade de princípios jurídicos dotados de mandamentos morais e presentes na prática constitucional dos Estados democráticos contemporâneos. Não se pode negar que o mesmo vem cumprindo a contento essa tarefa de aproximação entre direito e moral, aproximação esta que prega uma conexão contingente entre tais institutos jurídicos.

\section{A REFORMULAÇÃO - E NÃO A SUPERAÇÃO DEFINITIVA - DA PERSPECTIVA POSITIVISTA DE SE CONCEBER, COMPREENDER E APLICAR O DIREITO}

Apesar da crença generalizada de que o positivismo jurídico está em crise e que a sua superação é inevitável, um olhar mais profundo faz com que tal pensamento seja rechaçado, visto que houve a renovação dessa doutrina, a qual passou a aceitar que os valores morais, de certa forma e em certa medida, influenciam o direito e o modo de aplicação do mesmo pelo juiz. Isso quer dizer, na verdade, que, o que há, hoje, é o ressurgimento e a reestruturação de um modelo teórico que já era - e continua a ser - dominante.

Nesse ínterim, essa variante refinada tem reconhecido a valorização da Constituição, principalmente no que atine a seus aspectos materiais e substanciais. Outrossim, caminha-se à aceitação de valores morais no interior da ordem jurídica e, repisa-se, sem que isso faça com que a própria doutrina do positivismo jurídico seja autodestruída ou autonegada.

Já foi demonstrado que, após intensas críticas e constantes censuras dirigidas aos teóricos positivistas, a doutrina tivera que se reformular, passando a reconhecer que, atualmente, é inconcebível que a aplicação da norma deixe de levar em consideração valores principiológicos morais, devido ao fato da Constituição ser um instrumento normativo.

Ora, o positivismo jurídico inclusivo não pretende justificar as práticas jurídicas de imposição coercitiva com base em seus resultados, pelo contrário, busca-se descrever a forma, a estrutura e o conteúdo comum dos sistemas jurídicos, a fim de melhor vislumbrar a regulação social, a qual se relaciona com a moral. ${ }^{57}$

A aceitação pelo paradigma positivista dominante, ainda que inclusivo,

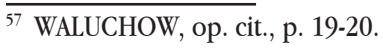


de uma moral reconhecida pelo ordenamento jurídico, faz com que os ideais de justiça, equidade e moralidade não sejam renegados a segundo plano. A norma posta pelo Estado obedece aos critérios de legitimidade e validade formal, porém, essas mesmas regras acabam por reconhecer e aceitar princípios como jurídicos e, portanto, atendem às exigências do constitucionalismo democrático na defesa e salvaguarda dos direitos fundamentais, bem como na supremacia da Carta Maior como documento jurídico, tanto processual quanto material.

Sendo assim, a aplicação do direito pelo juiz leva em consideração essa moralidade, mas sempre dentro dos limites do ordenamento, pois a segurança e certeza jurídicas também são valores a serem respeitados e alcançados em uma sociedade democrática. Isso significa dizer que, embora se permita - e admita-se uma discricionariedade do magistrado e a consequente relativização da norma posta pelo Estado-legislador quando haja necessidade de uma interpretação valorativa, o Judiciário deve respeitar os limites legais e substanciais que o próprio sistema jurídico lhe impõe.

Tem-se, portanto, a ligação entre reconhecimento jurídico da norma com a moralidade, da legalidade com a valoração e da autoridade com a justiça constitucional. Com a reformulação do direito positivo pela sua variante inclusiva, a convergência entre o paradigma dominante positivista e o constitucionalismo democrático torna-se possível, demonstrando que direito e moral não se constituem, necessariamente, em institutos jurídicos antinômicos e sem implicações mútuas, visto que há uma conjugação entre valores procedimentais e substantivos.

Em uma primeira vista de análise, seria possível tecer a afirmação de que os muitos avanços da doutrina positivista, especialmente por meio do denominado positivismo jurídico inclusivo, teriam aperfeiçoado tanto que, esse desenvolvimento, acabaria por abrir mão dos seus próprios postulados identificadores, principalmente, no que tange à compreensão da relação entre o direito e a moral. Entretanto, Sgarbi ${ }^{58}$ revela que não há oposição e muito menos contradição entre a inclusão contingente de referências de validade moral com o positivismo, visto que as incluir importa em reconhecer um padrão avaliativo do que se produz juridicamente. Ademais, nada disso é surpreendente quando se assente que a presença de tais referências está longe de ser ruim ao direito positivo.

\footnotetext{
${ }^{58}$ SGARBI, Adrian. Validade e obrigatoriedade: o dever jurídico no centro da tormenta. In: DIMOULIS, Dimitri; DUARTE, Écio Oto (Coord.). Teoria do direito constitucional: superação ou reconstrução do positivismo jurídico?. São Paulo: Método, 2008, p. 53-54.
} 
Todavia, diante de uma observação mais atenta, apurada e crítica, o que ocorre, na realidade, é que tais avanços do positivismo jurídico conseguem promover a harmonização para com a nova realidade do Estado constitucional e democrático de Direito, sistemas os quais acabam convergindo potencialmente.

A este respeito, Dimoulis e Lunardi ${ }^{59}$ salientam que o fato de o ordenamento jurídico valer-se de normas principiológicas não contraria ensinamentos do positivismo jurídico, muito menos causa alguma indigestão aos seus doutrinadores. Tal conclusão decorre de um intenso estudo das obras dos adeptos desta escola.

É necessário entender que para definir ou conceituar "Direito", nos dias atuais, é preciso levar em consideração que o mesmo deve estar conceitualmente ligado à realização de determinados valores morais - afastando-se qualquer antítese, anacoluto ou oximoro -, bem como deve estar atento ao cumprimento de determinadas finalidades, as quais ultrapassam o vetor da segurança jurídica, sem, no entanto, desconhecê-lo.

Como se observa, o próprio Waluchow ${ }^{60}$ aduz que se deve permitir que as pautas de moralidade e a racionalidade funcionem como relativamente determinantes ao significado das leis válidas. Nesta mesma senda, os dizeres de Soper ${ }^{61}$ acabam por revelar que, se o cerne do positivismo afirma que não é necessário que o direito reproduza certas demandas da moral, ainda assim os padrões morais podem ser relevantes para as decisões jurídicas de forma contingente conforme o que determinam as regras sociais.

O direito, por conseguinte, deve cumprir uma função emancipatória e assim o faz quando se depara com uma realidade social complexa - da qual ele surge e para a qual ele retorna -, comprometendo-se em melhorá-la por meio de institutos jurídicos aperfeiçoados. Isto é almejado pelo positivismo jurídico inclusivo. Sendo assim, não há mais que se falar que o positivismo jurídico - pelo menos em sua versão inclusiva - mantém uma hermenêutica insuficiente e, principalmente, negativa.

Desta forma, pode-se constatar que, nas últimas décadas, a própria teoria do direito de caráter positivista desenvolveu-se a ponto de relativizar a defesa do rigor normativo meramente formal, de modo que passou a reconhecer o direito como um complexo sistema de regras não destituído de possibilidades de contato para com a moral. Portanto, tais mudanças percebidas, atualmente, apontam não para uma

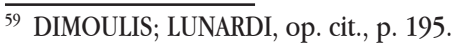

${ }^{60}$ WALUCHOW, op. cit., p. 22.

${ }^{61}$ SOPER, E. P. Legal theory and the obligation of a judge. In: COHEN, M (Coord.). Ronald Dworkin and the contemporary jurisprudence. Londres: Duckworth, 1983, p. 19. 
superação da ótica positivista de se compreender e conceituar o direito, mas frisa-se, para um aprimoramento do paradigma positivista dominante.

Neste sentido, Eustáquio ${ }^{62}$ pronuncia-se que a (suposta) crise do positivismo acabou estabelecendo profundas transformações sistêmicas, porém, em nenhum momento isso denotou sua desnaturação ou enfraquecimento, demonstrando-se muito mais a adaptação a uma nova maneira de legislar, visto que o positivismo, na era contemporânea, distanciou-se do caráter totalitário da lei e, por conseguinte, vinculou-se a sua natureza direcionadora, adentrando-se em um novo limiar, este denominado de "recodificação".

Deste modo, aduz-se aos ensinamentos de Sanchís, ${ }^{63}$ para o qual, a partir do momento que se resolvem conflitos jurídicos, acaba-se por oferecer respostas morais, as quais estão em perfeita lógica com o raciocínio jurídico, no qual há a conjugação de argumentos advindos do direito estrito plasmados nos argumentos derivados da filosofia da justiça.

Portanto, há motivos cabais para que se considere o positivismo jurídico inclusivo como viável e em pleno compasso com o neoconstitucionalismo. Segundo Dimoulis: ${ }^{64}$ "O positivismo jurídico não impede a avaliação moral, nem a crítica política ao direito [...]".

Ao contrário do que se pode pensar, intenta observar que não se está diante de um momento de rompimento estrutural, mas de profundas mudanças na maneira de se conceituar e se compreender o próprio direito positivo. De fato, as velhas estruturas rígidas do positivismo jurídico já se constatam ultrapassadas e, por isso, foi necessário repensá-lo, moldá-lo. O positivismo jurídico inclusivo já surgiu, precisando sair de seu estado de latência, a fim de ser acolhido, mediante melhor compreensão por parte de todos aqueles responsáveis, de certa forma e em determinada medida, pela construção do direito. Neste sentido, Dimoulis: ${ }^{65}$

Não é aconselhável demonizar o positivismo com acusações fantasiosas, contrapondo às realidades do mundo jurídico o quadro idílico de um direito justo e moralmente adequado, ou afirmando que o positivismo é uma teoria ultrapassada no momento em que se constata mundialmente sua vitalidade teórica.

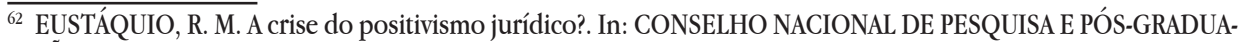
ÇÃO EM DIREITO, 16., 2007, Belo Horizonte. Anais do XVI Congresso Nacional do CONPEDI. Belo Horizonte, 2007 , p. 9.

${ }^{63}$ SANCHÍS, Luis Prieto. Constitucionalismo y positivismo. Ciudad de Mexico: Fontamara, 1999, p. 94.

${ }^{64}$ DIMOULIS, op. cit., p. 273.

${ }^{65}$ Ibidem, p. 273.
} 


\section{CONCLUSÃO}

As constantes e profundas transformações ocorridas na sociedade exigem do fenômeno jurídico um olhar mais cuidadoso para com os anseios e necessidades humanas. O direito, assim, deve debruçar-se em renovações que acompanhem o ritmo acelerado de uma sociedade caracterizada pela complexidade, multiplicidade e mutabilidade. Entretanto, há um estigma jurídico, principalmente encabeçado pelos teóricos neoconstitucionais, que aponta o positivismo como sendo uma doutrina que reduz o direito à força, como teoria que a legitima e como corrente que se mantém distante de valores como justiça, equidade e moralidade.

Nesse sentido, muitas críticas foram dirigidas ao positivismo jurídico por parte dos adeptos do neoconstitucionalismo, no afã de demonstrar suas fraquezas e, acima de tudo, revelar a necessária - e imediata - substituição - e superação de uma antiga visão jurídica da sociedade, visto que o "novo" fazia-se presente. Todavia, em que pese muitos argumentos do neoconstitucionalismo serem, de fato, contundentes, a maioria deles incorre na denominada straw man fallacy, visto dirigirem oposições e críticas à caricatura da teoria positivista e não, necessariamente, aos reais conteúdos adotados pelos seus defensores.

Todavia, nota-se que, assim como a sociedade evolui, as doutrinas também o fazem. E isso não foi diferente com o positivismo jurídico. Nesta esteira, essa versão refinada conseguiu impugnar, especificamente, cada censura oposta à Escola Positivista pelos teóricos neoconstitucionalistas. Diante disso, vislumbra-se que o processo de constitucionalização amolda-se ao positivismo jurídico moderado, estruturando uma nova perspectiva que impende a necessidade de não se abandonar ou deixar para trás a mentalidade do positivismo jurídico. Repisa-se que se busca defender o não abandono do positivismo jurídico, mas ao menos, soltar-se das velhas estruturas e algemas rígidas que muito estruturaram a mentalidade dessa escola de pensamento, sendo a chave, justamente, o positivismo inclusivo.

Por isso, defende-se que o Positivismo Jurídico é uma doutrina má compreendida, pois a identificação de tal Escola como sendo uma vertente legalista e conservadora não merece prosperar, visto que muitos positivistas - se não a maioria - não acreditam em primado de completude do sistema jurídico, decisão mecânica e subsuntiva, neutralidade avalorativa, em perfeição normativa, em segurança jurídica absoluta e em separação entre Direito e moral. Neste interregno, a abordagem 
desmistifica o Positivismo Jurídico, demonstrando que há possibilidade - através da versão positivo-inclusivista -, sim, de conciliá-lo com o constitucionalismo democrático, porquanto já demonstrado que direito e moral são institutos não antinômicos.

Ademais, não se trata de uma tentativa de "salvar" o positivismo jurídico, visto que a crise é meramente hipotética, quando da constatação de uma reformulação da escola, a qual veio tirar a si mesmo do "descrédito" que tanto lhe era imputado. Portanto, a variante inclusiva não é uma espécie doutrinária que tem como função ser um aparelho respiratório que dá sobrevida a seu gênero teórico, mas visa dirimir os argumentos de defasagem jurídico-social que o positivismo supostamente incorre.

Ora, o fato de uma doutrina adotar premissas - que antes não adotava não tem o condão de atribuir-lhe características que vão de encontro com os seus próprios postulados. Precisa ser extinta a noção de que nenhum positivista defende valores e princípios, pois, é trivial que qualquer sistema jurídico necessita, minimamente, incorporar ao direito normas que desempenham importantes papéis na própria aplicação do fenômeno jurídico, sem que isso possa suscitar o abandono parcial e silencioso ou total e escancarado dos adeptos de algum tipo de positivismo.

Desta forma, no presente momento da teoria do direito, faz-se mister adotar uma postura doutrinária corajosa e reconhecer que o positivismo jurídico não se encontra em descompasso e muito menos desalinhado ou desajustado para com a nova realidade social, visto que sua vertente inclusiva consegue conciliar o sistema normativo de regras com a carga valorativa e aberta dos princípios, bem como torna possível a conciliação entre direito e moral, mesmo que em caráter contingencial.

Com efeito, é notório que não há mais espaços para que se conceba o direito como uma ciência sem uma finalidade intrinsecamente construtiva. Isto não seria possível e muito menos desejável. Deste modo, o positivismo jurídico refinado não pretende desvincular a compreensão teleológica do direito, mas garantir graus mínimos de justiça que, em certos momentos, podem ir além do ideal de segurança jurídica, sem, contudo, negá-lo ou rechaçá-lo. Desta maneira, o trabalho conclui que, ao contrário da crença na superação do paradigma positivista dominante por significativa parcela doutrinária neoconstitucional, não se está diante de um momento de rompimento estrutural, senão de marcantes mudanças na maneira de se conceituar e se compreender o próprio direito, mister o positivo. Afinal, o avanço e o aperfeiçoamento devidos acabaram por demarcar um refinamento teórico e não o seu esgotamento e ultrapassagem. 


\section{REFERÊNCIAS}

ALDAY, Rafael Escudero. Los calificativos del positivismo jurídico: el dabate sobre la incorporación de la moral. Madrid: Civitas, 2004.

ALDAY, Rafael Escudero. Algunos argumentos frente al positivismo jurídico incluyente. In: DIMOULIS, Dimitri; DUARTE, Écio Oto (Coord.). Teoria do direito constitucional: superação ou reconstrução do positivismo jurídico?. São Paulo: Método, 2008.

ALEXY, Robert. El concepto y la validez del derecho. 2. ed. Barcelona: Gedisa, 2004.

BERMEJO, Juan Manuel Pérez. Coherencia y sistema jurídico. Madrid: Marcial Pons, 2006.

COLEMAN, Jules. Negative and positive positivism. In: COHEN, Marshall (Org.). Ronald Dworkin and the contemporary jurisprudence. Totowa: Rowman \& Allanheld, 1984.

COLEMAN, Jules. Incorporationism, conventionality and the practical difference thesis. In: COLEMAN, Jules (Org.). Hart's postscript: essays on the postscript to the concept of law. Oxford: Oxford University Press, 2001.

COLEMAN, Jules. The practice of principle: in defense of a pragmatist approach to legal theory. Oxford: Oxford University Press, 2003.

DIMOULIS, Dimitri. Positivismo jurídico: introdução a uma teoria do direito e defesa do pragmatismo jurídico-político. São Paulo: Método, 2006.

DIMOULIS, Dimitri; LUNARDI, Soraya. O positivismo jurídico diante da principiologia. In: DIMOULIS, Dimitri; DUARTE, Écio Oto (Coord.). Teoria do direito constitucional: superação ou reconstrução do positivismo jurídico?. São Paulo: Método, 2008.

DUARTE, Écio Oto; POZZOLO, Susanna. Neoconstitucionalismo e positivismo jurídico: as faces da teoria do direito em tempos de interpretação moral da constituição. São Paulo: Landy, 2006. 
DWORKIN, Ronald. O império do direito. São Paulo: Martins Fontes, 2014.

ETCHEVERRY, Juan Bautista. El debate sobre el positivismo jurídico incluyente: un estado de la cuestión. Ciudad de México: Universidad Nacional Autónoma de México, 2006.

EUSTÁQUIO, R. M. A crise do positivismo jurídico?. In: CONSELHO NACIONAL DE PESQUISA E PÓS-GRADUAÇÃO EM DIREITO, 16., 2007, Belo Horizonte. Anais... Belo Horizonte: Congresso Nacional do CONPEDI, 2007.

FINNIS, John. Natural law: the classical tradition. In: COLEMAN, Jules; Shapiro, Scott (Org). The Oxford handbook of jurisprudence \& philosophy of law. Oxford: Oxford University Press, 2002.

GARDNER, John. Legal positivism: $51 / 2$ myths. American journal of jurisprudence, Notre Dame, v. 46, n. 12, Jan. 2001. Disponível em: < http://scholarship.law.nd.edu/ ajj/vol46/iss1/12/>. Acesso em: 21 abr. 2015.

HART, H. L. A. O conceito de direito. São Paulo: Martins Fontes, 2012.

HIMMA, Kenneth Einar. Inclusive legal positivism. In: COLEMAN, Jules; SHAPIRO, Scott (Org). The Oxford handbook of jurisprudence \& philosophy of law. Oxford: Oxford University Press, 2002.

KELSEN, Hans. Teoria pura do direito. São Paulo: Martins Fontes, 2000.

KRAMER, Matthew. In defense of legal positivism: law without trimmings. Oxford: Oxford University Press, 2003.

LYONS, D. Principles, positivism and legal theory. Yale law journal, Connecticut, v. 87, n. 2, Dez. 1977. Disponível em: < http://www.jstor.org/stable/795657>. Acesso em: 21 abr. 2015.

MACEDO JÚNIOR, Ronaldo Porto. Do xadrez à cortesia: Dworkin e a teoria do direito contemporânea. São Paulo: Saraiva, 2014.

MARMOR, Andrei. Exclusive legal positivism. In: COLEMAN, Jules; Shapiro, Scott (Org.). The Oxford handbook of jurisprudence \& philosophy of law. Oxford: Oxford University Press, 2002. 
MORESO, José Juan. En defensa del positivismo jurídico inclusivo. In: NAVARRO, Pablo; REDONDO, M. Cristina (Org.). La relevancia del derecho: ensayos de filosofia moral, jurídica y política. Barcelona: Gedisa, 2002.

POZZOLO, Susanna. Neocostituzionalismo e positivismo giurídico. Torino: Giappichelli, 2001.

RAZ, Joseph. The authority of law: essays on law and morality. Oxford: Oxford University Press, 1979.

RAZ, Joseph. Legal principles and the limits of law. In: COHEN, Marshall (Org.). Ronald Dworkin and contemporary jurisprudence. Totowa: Rowman \& Allanheld, 1984.

ROSSI, A. Neoconstitucionalismo e a superação da perspectiva positivista do direito. 2011. 210f. Tese (Doutorado em Direito) - Universidade Federal do Paraná, Curitiba. 2011

SANCHÍS, Luis Prieto. Constitucionalismo y positivismo. Ciudad de Mexico: Fontamara, 1999.

SARMENTO, Daniel. O neoconstitucionalismo no Brasil: riscos e possibilidades. In: FELLET, André; PAULA, Daniel de; NOVELINO, Marcelo (Org.). As novas faces do ativismo judicial. Salvador: Juspodivm, 2011

SGARBI, Adrian. Validade e obrigatoriedade: o dever jurídico no centro da tormenta. In: DIMOULIS, Dimitri; DUARTE, Écio Oto (Coord.). Teoria do direito constitucional: superação ou reconstrução do positivismo jurídico?. São Paulo: Método, 2008.

SHAPIRO, Scott J. The "Hart-Dworkin" debate: a short guide for the perplexed. Public law and legal theory working paper series, Michigan, n. 47, Mar. 2007. Disponível em: <http://ssrn.com/abstract=968657> . Acesso em: 20 abr. 2015.

SOPER, E. P. Legal theory and the obligation of a judge. In: COHEN, M (Coord.). Ronald Dworkin and the contemporary jurisprudence. Londres: Duckworth, 1983. 
WALUCHOW, Wilfrid. Positivismo juridico incluyente. Madrid: Marcial Pons, 2007.

Recebido em: 10 de setembro de 2016 Aceito em: 19 de junbo de 2017 